\title{
The role of memories on health-related quality of life after intensive care unit care: an unforgettable controversy?
}

This article was published in the following Dove Press journal:

Patient Related Outcome Measures

4 June 2016

Number of times this article has been viewed

\author{
Lotti Orwelius ${ }^{1-4}$ \\ Armando Teixeira-Pinto 2,5 \\ Cristina Lobo ${ }^{2}$ \\ Altamiro Costa-Pereira ${ }^{1,2}$ \\ Cristina Granja ${ }^{1,2,6,7}$ \\ 'Department of Health Information \\ and Decision Sciences, Faculty of \\ Medicine of Porto, Porto, Portugal; \\ ${ }^{2}$ CINTESIS - Centre for Research \\ in Health Technologies and Health \\ Systems, Faculty of Medicine of Porto, \\ Porto, Portugal; ${ }^{3}$ Department of \\ Intensive Care, Linköping University, \\ County Council of Ostergötland, \\ Linköping, Sweden; ${ }^{4}$ Department of \\ Clinical and Experimental Medicine, \\ Linköping University, Linköping, \\ Sweden; ${ }^{5}$ Screening and Test \\ Evaluation Program, Sydney School of \\ Public Health, University of Sydney, \\ Sydney, NSW, Australia; ${ }^{6}$ Department \\ of Emergency and Intensive Care \\ Medicine, Algarve Hospital Centre, \\ Algarve, Portugal; ' Department of \\ Biomedical Sciences and Medicine, \\ University of Algarve, Algarve, \\ Portugal
}

Background: Decreased health-related quality of life (HRQoL) is a significant problem after an intensive care stay and is affected by several known factors such as age, sex, and previous health-state. The objective of this study was to assess the association between memory and selfreported perceived HRQoL of patients discharged from the intensive care unit (ICU).

Methods: A prospective, multicenter study involving nine general ICUs in Portugal. All adult patients with a length of stay $>48$ hours were invited to participate in a 6-month follow-up after ICU discharge by answering a set of structured questionnaires, including EuroQol 5-Dimensions and ICU memory tool.

Results: A total of 313 (52\% of the eligible) patients agreed to enter the study. The median age of patients was 60 years old, $58 \%$ were males, the median Simplified Acute Physiology Score II (SAPS II) was 38, and the median length of stay was 8 days for ICU and 21 days for total hospital stay. Eighty-nine percent $(n=276)$ of the admissions were emergencies. Seventy-eight percent $(\mathrm{n}=234)$ of the patients had memories associated with the ICU stay. Patients with no memories had 2.1 higher chances $(P=0.011)$ of being in the bottom half of the HRQoL score $(<0.5$ EuroQol 5-Dimensions index score). Even after adjusting for pre-admission characteristics, having memories was associated with higher perceived HRQoL (adjusted odds ratio $=2.1, P=0.022$ ).

Conclusion: This study suggests that most of the ICU survivors have memories of their ICU stay. For the ICU survivors, having memories of the ICU stay is associated with a higher perceived HRQoL 6 months after ICU discharge.

Keywords: health-related quality of life, memory disturbances, critical care, outcome

\section{Introduction}

Decreased health-related quality of life (HRQoL) has been recognized as a significant problem occurring after a stay in an intensive care unit (ICU) when compared to the general population with similar age and sex distribution. ${ }^{1,2}$ During the last decade there has been an increasing focus on HRQoL, which together with mortality, has been found to be the most important outcome measure after critical care. ${ }^{1,3}$ A considerable number of studies have explored potential determinants of poor HRQoL after ICU stay. A recent systematic review identified older age, female sex, high severity of illness (Acute Physiology and Chronic Health Evaluation [APACHE] score), acute admission type, longer length of stay, or non-healthy previous state, as important factors associated with low HRQoL after ICU stay. ${ }^{1}$

We have previously examined the role of memory disturbances on posttraumatic stress disorder (PTSD) and we found that a higher risk of developing PTSD was sig-
Correspondence: Lotti Orwelius Department of Intensive Care, Linköping University, 58I 85 Linköping, Sweden

Tel +4670322 I32I

Fax: +46 I0 I038649

Email lotti.orvelius@regionostergotland.se 
nificantly associated with not remembering the hospital stay before ICU admission. ${ }^{4}$ The aim of this study is to assess the association between memory and self-reported perceived HRQoL of patients 6 months after discharge from ICU. We hypothesized that having memories of the ICU or hospital stay might be better than not having memories at all and could have a positive impact on the perceived HRQoL.

\section{Methods}

This prospective multicenter study is part of a larger study involving 17 Portuguese ICUs ${ }^{5}$ and conducted by the JMIP (Jornadas de Medicina Intensiva da Primavera) Study Group. Nine of these 17 ICUs agreed to formally followup their survivors, and collect data for the present study. Details of study design, definitions, data collection and management are provided elsewhere. ${ }^{4}$ The participating ICUs are listed in the Acknowledgments section. The study was submitted and approved by the Instituto de Bioética, Universidade Católica Portuguesa ethics committee and the ethics committees from each participating hospital: Hospital Pedro Hispano, Matosinhos; Hospital Geral de Santo António, Porto; Centro Hospitalar de Vila Nova de Gaia, Vila Nova de Gaia; Centro Hospitalar Peso da Régua Vila Real, Vila Real; Hospital de S. Sebastião, Santa Maria da Feira, Feira; Centro Hospitalar dos Covões, Coimbra; Hospital do Desterro, Lisboa; Hospital de Santa Maria, Lisboa; and Hospital de Beja, Beja.

\section{Patients}

All adult patients ( $\geq 18$ years), who were admitted consecutively to any of the nine ICUs between January 1, 2005, and June 30, 2005, remained in the ICU for more than 48 hours, and were alive 6 months after ICU discharge were eligible and invited to participate in the study.

At 6 months after ICU discharge, a letter containing detailed information of the study, together with a set of structured questionnaires were sent by mail with either a preaddressed and prepaid return envelope or to be returned by hand where a follow-up consultation took place. Informed consent was obtained at the time of the follow-up consultation, where applicable. Thus, as consent was implicit in returning the questionnaire, the need for additional informed consent was waived.

Collected ICU variables included, severity of disease at admission using Simplified Acute Physiology Score II (SAPS II), duration of stay at ICU and hospital, and admission diagnostic category (medical, scheduled surgery, non-scheduled surgery, and trauma).

\section{Questionnaires}

A set of structured questionnaires, including the EuroQol 5-Dimensions (EQ-5D), and ICU memory tool, was mailed to the patients 6 months after ICU discharge. Additional questions were added to these questionnaires, namely about the patient's background; sex and age, employment status, level of education, and previous health state. Based on individual clinical registries and on direct questioning of patients during the follow-up consultation, previous health state was evaluated by the patient's physician according to three categories: healthy, chronic non-disabling diseases (ie, able to work or perform normal daily activities), and chronic disabling diseases (ie, unable to work or undertake normal daily activities). Each participating physician classified all patients to one of these three categories. For the purpose of analysis we divided patients into two groups: previously healthy and previously non-healthy (with chronic non-disabling disease or chronic disabling disease).

\section{EQ-5D}

HRQoL was assessed by the original EQ-5D questionnaire. ${ }^{6,7}$ This is a generic instrument, developed and applied by an international multidisciplinary research group. The instrument is well-known internationally and has been recommended as one of the two best instruments for measuring HRQoL in critical care, ${ }^{8}$ and has been validated in the ICU injured population. ${ }^{9,10}$ The EQ-5D comprises two parts. The first involves a health state classification scheme of five items (mobility, self-care, usual activities, pain/discomfort, and anxiety/depression), each having three alternatives $(1=$ no problems, $2=$ moderate problems, and $3=$ severe problems). Calculating a single index score combines these five dimensions. The combination of answers on the five items represents the health state. In all, there are $243\left(=3^{5}\right)$ possible health states. Each health state has a preference value attached to it. The index value of a particular health state thus indicates the preference for being in that health state in relation to death, which has been set equal to 0 and best possible health (eg, no problems on any of the five items) which has been set to 1.0. Some of the health states have been valued as being worse than death and therefore has a negative index value. For instance, the worst possible EQ-5D health state (eg, severe problems on all five EQ-5D items) has an index value of -0.59 . The second part of the EQ-5D is a visual analog scale, ranging from 0 (worst possible health state) to 100 (best possible health state). For the purpose of this study, only data from the index score will be reported. 


\section{ICU memory tool}

The ICU memory tool ${ }^{11}$ was developed to assess recall of factual and delusional memories from the hospital and ICU stay. It consists of eight questions about factual memories of events, for example suction in the endotracheal tube; memories of feelings, such as anxiety or pain; and delusional memories, for example hallucinations or nightmares. Further it includes six additional questions, three to assess the presence of any other amnesic period, including admission to hospital and ICU, and discharge from ICU, and three questions to assess quality of re-experiencing ICU memories after ICU discharge, eg, presence of intrusive memories. The instrument has been used both for clinical interviews ${ }^{11}$ and as self-completed questionnaire. ${ }^{4}$ Patients are asked for both recall items chosen from a checklist as well as a brief description relating to any ICU memories after discharge.

For the main analysis we divided the patients in two groups: those with memories and those with no memories. In addition, for the patients with memories we considered three groups: patients with only factual memories, patients with only delusional memories, and patients with both factual and delusional memories.

\section{Statistical methods}

The EQ-5D score presented an asymmetric distribution with strong "ceiling" and "floor" effects. Therefore, we chose to analyze a dichotomized version of the score by using the cut-off 0.5 to define higher and lower HRQoL. This cut-off corresponds to classify patients who reported at least one severe problem in one of the EQ-5D dimensions as having a lower HRQoL (EQ-5D score $<0.5$ ), and patients with no severe problems in all the dimensions as having higher HRQoL (there is one exception to this correspondence between the 0.5 cut-off and the EQ-5D states, which is the state with a severe problem in the "usual activities" dimension and no problems in the other dimensions, but in our experience this state rarely occurs in practice and it was not observed in our sample).

The ICU memories were analyzed in two ways. First, we considered only two categories: having ICU memories vs no memories. Then we considered different types of memories grouped in four categories: no memories; only factual memories; both delusional and factual memories; and only delusional memories.

Data are summarized as medians and interquartile range for continuous variables and percentages for categorical ones. The association of the dichotomized EQ-5D score with ICU memories, baseline and clinical variables, was described with odds ratios (ORs) for higher HRQoL obtained through logistic regressions.

Finally, we used a multivariable logistic regression to model the chances of higher HRQoL and compute the ORs for the ICU memories (separately for the version of the variable with two categories and four categories) adjusted to baseline and clinical factors. These two models were first initiated with the variables that presented univariate ORs with associated $P$-values $<0.2$. A backward stepwise-like approach was then used in this subset of variables, always maintaining the ICU memory variable in the model and sequentially removing the covariates that were not statistically significant. $P$-values $<0.05$ were considered statistically significant. The statistical analyses were performed using SPSS version 21.0 (IBM Corporation, Armonk, NY, USA ).

\section{Missing data}

The calculation of the global scores for each instrument involves a weighted sum of the questions and thus requires all questions to be answered. If one question is left unanswered, the score cannot be directly computed. We had 22 and three incomplete questionnaires, for the EQ-5D and ICU memory tool, respectively. If the questionnaire was not at least half answered, it was excluded from the analysis. However, most of the incomplete questionnaires had only one question unanswered. For those, we computed the partial score using the answered questions. This partial score was then rescaled to the original scale taking into account the weight of the unanswered questions. For example, if a patient had only $2 / 3$ of the questionnaire complete with a partial score of 30 , the final score would be computed as 45 (if the unanswered questions had the same weight as the answered ones). The underlying assumption for this approach is that the unanswered question(s) follow a similar pattern to the answered ones. We also conducted a sensitivity analysis by using only complete observations.

For missing data in the demographic variables we only report complete cases.

\section{Results}

A total of 599 patients met the inclusion criteria, and 313 patients (52\%) answered the questionnaire at 6 months (Figure 1). There were no significant differences between the respondents $(n=313)$ and the non-respondents $(n=286)$ concerning background and ICU variables (Table S1). Three patients did not complete half of the EQ-5D and were excluded from the study, and the final study population comprised 310 patients. 


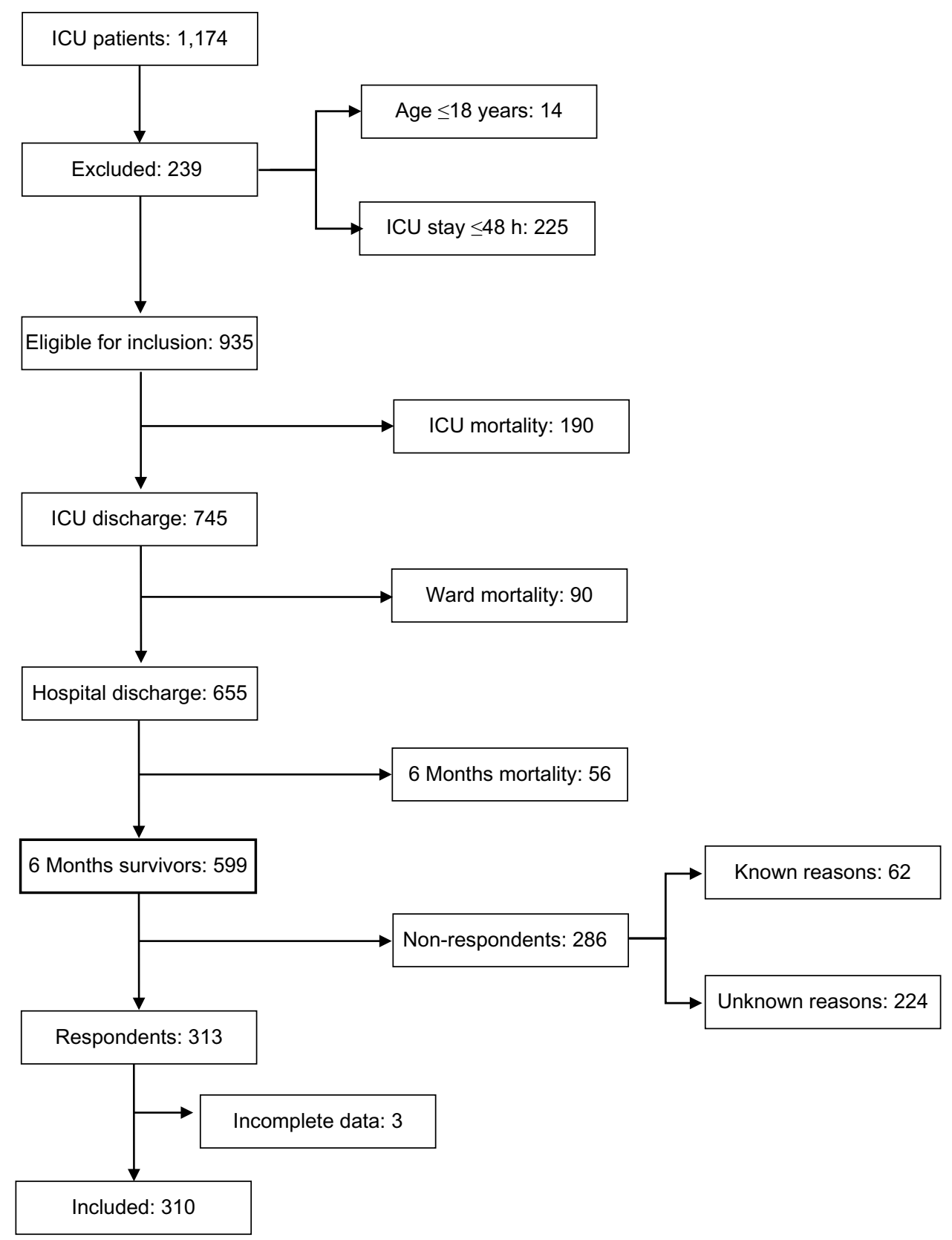

Figure I Patient inclusion chart.

Abbreviations: ICU, intensive care unit; h, hour(s).

The clinical and demographic characteristics of patients in the study are shown in Table 1. Overall, $22 \%(n=67)$ of the patients reported having no memories associated with their ICU stay, and $78 \%(n=234)$ had memories. For the patients with memories, $50 \%(\mathrm{n}=117)$ reported having solely factual memories, $6 \%(n=15)$ reported solely delusional memories, and $44 \%(n=102)$ reported delusional plus factual memories (Table 1). Patients who reported having memories had significantly lower SAPS, had a shorter ICU and hospital stay, were less healthy before ICU admission, and were less likely to have been admitted to ICU due to trauma (data not shown).
The overall median index score value for HRQoL was 0.66 (interquartile range: [0.26, 0.85]). Data for comparison of the patients with perceived higher HRQoL $(\geq 0.5)$ and the patients with perceived decreased level of HRQoL $(<0.5)$ respectively, are shown in Table 2.

Thirty percent of the patients who reported low HRQoL and $18 \%$ of the patients with perceived high HRQoL had no memories of the ICU (Table 2). This corresponds to a two-fold increase in the odds of higher levels of HRQoL for patients with memories when compared with patients with no memories $(\mathrm{OR}=2.1, P=0.011)$. 
Table I Clinical and demographic characteristics of 310 patients enrolled in the study by ICU memories status

\begin{tabular}{|c|c|c|c|c|c|}
\hline \multirow[b]{3}{*}{ Age (years), median (IQR) } & \multirow[b]{2}{*}{ Total } & \multicolumn{3}{|c|}{ Memories of ICU stay } & \multirow{3}{*}{$\begin{array}{l}\text { P-value* } \\
0.935\end{array}$} \\
\hline & & No $(n=67,22 \%)$ & \multicolumn{2}{|c|}{ Yes $(n=234,78 \%)$} & \\
\hline & $60 \quad(50-70)$ & $62(50-69)$ & 60 & $(50-69)$ & \\
\hline SAPS, median (IQR) & $38 \quad(38-47)$ & $41 \quad(32-50)$ & 36 & $(28-46)$ & 0.012 \\
\hline LoS ICU, median (IQR) & $8 \quad(5-13)$ & $10(7-16)$ & 7 & $(5-11)$ & 0.004 \\
\hline LoS hospital, median (IQR) & $21 \quad(14-32)$ & $23 \quad(16-45)$ & 20 & $(13-30)$ & 0.017 \\
\hline \multicolumn{6}{|l|}{ Sex, n (\%) } \\
\hline Female & $129(42)$ & $25 \quad(37)$ & 101 & (43) & 0.392 \\
\hline Male & $|8|(58)$ & $42 \quad(63)$ & 133 & (57) & \\
\hline \multicolumn{6}{|l|}{ Previous health state, $\mathrm{n}(\%)$} \\
\hline Healthy & $126(43)$ & $32(56)$ & 92 & (40) & 0.032 \\
\hline Non-healthy & $165(57)$ & $25 \quad(44)$ & 136 & $(60)$ & \\
\hline \multicolumn{6}{|l|}{ Employment, n (\%) } \\
\hline Employed & $92 \quad(31)$ & $21 \quad(34)$ & 70 & (3I) & 0.701 \\
\hline Retired & 161 (54) & $33 \quad(54)$ & 122 & (54) & \\
\hline Other & $44 \quad(15)$ & $7 \quad(I I)$ & 35 & (15) & \\
\hline \multicolumn{6}{|l|}{ Education, n (\%) } \\
\hline Primary school not completed & $73 \quad(24)$ & $20 \quad(31)$ & 48 & (2I) & 0.225 \\
\hline Only primary school completed & $105(34)$ & $20 \quad(3 I)$ & 84 & (37) & \\
\hline More than primary school & $124(40)$ & $24 \quad(38)$ & 97 & (42) & \\
\hline \multicolumn{6}{|l|}{ Diagnostic category, n (\%) } \\
\hline Medical & $176(57)$ & $33 \quad(49)$ & 139 & (59) & 0.001 \\
\hline Trauma & $49 \quad(16)$ & $20 \quad(30)$ & 29 & (12) & \\
\hline Scheduled surgery & 34 (II) & 2 (3) & 31 & (13) & \\
\hline Non-scheduled surgery & $51 \quad(16)$ & $12(18)$ & 35 & (15) & \\
\hline \multicolumn{6}{|l|}{ Memories, n (\%) } \\
\hline No memories & $67 \quad(22)$ & $67 \quad(100)$ & - & & \\
\hline Only factual & 117 (39) & - & 117 & $(50)$ & \\
\hline Delusional and factual & $102(34)$ & - & 102 & (44) & \\
\hline Only delusional & $15 \quad(5)$ & - & 6 & (6) & \\
\hline
\end{tabular}

Notes: *Mann-Whitney $U$ test was used for continuous variables and chi-square test for categorical ones. The sums do not always add up to 310 patients given there were some missing data.

Abbreviations: ICU, intensive care unit; SAPS, Simplified Acute Physiology Score; LoS, length of stay; IQR, interquartile range.

When comparing by the type of memories during ICU stay, patients with only factual or a mix of factual and delusional memories showed a similar increase in the odds of high HRQoL (OR $=2.1, P$-value $=0.020$ and $\mathrm{OR}=1.9$, $P$-value $=0.048)$. Surprisingly, patients who only experienced delusional memories also presented an increase in the odds of higher HRQoL. However, the result is based on a very small group of patients and the OR is non-significant.

For the multivariable logistic model, only previous health state and education remained in the final model together with memories. Less educated patients and patients with previous health problems were more likely to be in the lower band of HRQoL. When adjusting for these two covariates, the association between memories and HRQoL remained similar.

A sensitivity analysis was conducted repeating the statistical analysis but using only the cases that fully completed the questionnaires $(n=288)$. The results were identical in terms of magnitude of the OR, but given the smaller sample sizes some of the estimates became non-significant (data not shown).

\section{Discussion}

Several findings should be highlighted in the present study: first, most of the ICU survivors $(78 \%)$ have memories of their ICU stay; second, having memories of the ICU is significantly associated with higher HRQoL. This suggests that, with regard to HRQoL, having memories of the ICU stay is better than having no memories at all. This is in line with our previous results containing the same database where we examined the role of memory disturbances on PTSD, ${ }^{4}$ and found that a higher risk of developing PTSD was significantly associated with not remembering the hospital stay before ICU admission. In the current study we cannot conclude if a patient's HRQoL is causally affected by having memories from their ICU stay or if being in a lower state of HRQoL causes patients to want to forget their ICU stay. However, this was not the aim of the study. Importantly, our results support the conclusions from two systematic reviews that a diary with accurate information from the intensive care period will fill the gap in memory 
Table 2 Comparisons of patients' characteristics according to their HRQoL EQ-5D score (low $<0.5$ and high $\geq 0.5)$ and the odds ratio $(n=310)$.

\begin{tabular}{|c|c|c|c|c|c|c|c|c|c|}
\hline \multirow[b]{2}{*}{ Age (years), median (IQR) } & \multicolumn{2}{|c|}{$\begin{array}{l}\text { Lower HRQoL } \\
(n=94)\end{array}$} & \multicolumn{2}{|c|}{$\begin{array}{l}\text { Higher HRQoL } \\
(n=216)\end{array}$} & \multirow{2}{*}{$\begin{array}{l}\text { Raw } \\
\text { odds ratio* } \\
0.99\end{array}$} & \multirow{2}{*}{$\begin{array}{l}\text { P-value } \\
0.110\end{array}$} & \multirow[t]{2}{*}{$\begin{array}{l}\text { Adjusted }^{a} \\
\text { odds ratio }\end{array}$} & \multirow[t]{2}{*}{$95 \% \mathrm{Cl}$} & \multirow[t]{2}{*}{$P$-value } \\
\hline & 63 & $(5 \mathrm{I}-73)$ & 59 & $(47-69)$ & & & & & \\
\hline SAPS, median (IQR) & 39 & $(32-50)$ & 37 & $(29-46)$ & 0.98 & 0.023 & & & \\
\hline LoS ICU, median (IQR) & 6 & $(6-13)$ & 7 & $(5-12)$ & 0.98 & 0.079 & & & \\
\hline LoS hospital, median (IQR) & 27 & $(17-47)$ & 20 & $(13-29)$ & 0.98 & $<0.001$ & & & \\
\hline \multicolumn{10}{|l|}{ Sex, n (\%) } \\
\hline Female & 41 & $(44)$ & 88 & $(4 I)$ & Ref & & & & \\
\hline Male & 53 & (56) & 128 & (59) & I.I & 0.637 & & & \\
\hline \multicolumn{10}{|l|}{ Previous health state, $\mathrm{n}(\%)$} \\
\hline Healthy & 27 & $(3 I)$ & 99 & (49) & Ref & & Ref & & \\
\hline Non-healthy & 60 & (69) & 105 & (5I) & 0.5 & 0.006 & 0.5 & $0.3-0.8$ & 0.009 \\
\hline \multicolumn{10}{|l|}{ Employment, n (\%) } \\
\hline Employed & 20 & $(23)$ & 72 & (34) & Ref & & & & \\
\hline Retired & 55 & (63) & 106 & $(50)$ & 0.5 & 0.039 & & & \\
\hline Other & 12 & (14) & 32 & (15) & 0.7 & 0.477 & & & \\
\hline \multicolumn{10}{|l|}{ Education, n (\%) } \\
\hline Primary school not completed & 35 & (39) & 38 & $(18)$ & Ref & & Ref & & \\
\hline Only primary school completed & 28 & (3I) & 77 & (36) & 2.5 & 0.004 & 2.2 & $\mathrm{I} . \mathrm{I}-4.4$ & 0.019 \\
\hline More than primary school & 27 & (30) & 97 & $(46)$ & 3.3 & $<0.001$ & 2.8 & I.5-5.4 & 0.003 \\
\hline \multicolumn{10}{|l|}{ Diagnostic category, n (\%) } \\
\hline Medical & 53 & $(56)$ & 123 & $(57)$ & Ref & & & & \\
\hline Trauma & 20 & $(2 I)$ & 29 & $(13)$ & 0.6 & 0.159 & & & \\
\hline Scheduled surgery & 6 & (6) & 28 & (13) & 2.0 & 0.145 & & & \\
\hline Non-scheduled surgery & 15 & (16) & 36 & $(17)$ & 1.0 & 0.923 & & & \\
\hline \multicolumn{10}{|l|}{ I) Memories, n (\%) } \\
\hline No memories & 29 & $(32)$ & 38 & $(18)$ & Ref & & Ref & & \\
\hline Memories & 63 & (68) & $17 \mid$ & $(82)$ & 2.1 & 0.011 & 2.1 & I.I-4.0 & 0.022 \\
\hline \multicolumn{10}{|l|}{ 2) Memories, n (\%) } \\
\hline No memories & 29 & $(32)$ & 38 & $(18)$ & Ref & & Ref & & \\
\hline Only factual & 31 & (34) & 86 & $(4 I)$ & 2.1 & 0.020 & 2.3 & I.I-4.7 & 0.024 \\
\hline Delusional and factual & 29 & (32) & 73 & (35) & 1.9 & 0.048 & 1.9 & $0.9-3.8$ & 0.093 \\
\hline Only delusional & 3 & (3) & 12 & (6) & 3.1 & 0.106 & 3.1 & $0.8-12.9$ & 0.115 \\
\hline
\end{tabular}

Notes: The sums do not always add up to 310 patients given there were some missing data. *Odds ratios are presented as the increase in the odds of higher HRQoL. ${ }^{2}$ The adjusted odds ratios' values were obtained through two logistic regressions. The first used the variable memories (I) with two categories and the second used the variable memories (2) with four categories. The adjusted odds ratios were computed with previous health state, education, and memories in the logistic model. The adjusted odds ratios for previous health state and education presented in the table refer to model I (the odds ratios for model 2 are similar). Significant $P$-values are shown in bold ( $P<0.05$ ). Abbreviations: HRQol, health-related quality of life; EQ-5D, EuroQol 5-Dimensions; Cl, confidence interval; Ref, reference; ICU, intensive care unit; SAPS, Simplified Acute Physiology Score; LoS, length of stay; IQR, interquartile range.

and act as a debriefing tool for the patient ${ }^{12,13}$ with a positive effect on HRQoL. ${ }^{14}$ To our knowledge, this is the first study establishing an association between memories of the ICU stay and HRQoL for the general ICU population alive at 6 months after discharge from ICU and, as such, it adds to our knowledge concerning determinants of HRQoL after ICU. Ringdal et $\mathrm{al}^{15}$ have shown, in a trauma cohort, that patients with delusional memories perceived a decreased HRQoL, measured with SF-36, compared with patients without memories. Their study, however, focused only on delusional memories in a very specific group of patients (trauma patients). The association between memories of the ICU stay and higher perceived HRQoL suggests the need to have a targeted sedation level and daily awakening periods for ICU patients . ${ }^{16,17}$ Third, perceived worst HRQoL is significantly associated with older age, retirement, lower level of education, non-healthy previous state, severity of illness (SAPS II) and longer duration of hospital stay. In our cohort as many as $24 \%(n=73)$ of the patients did not even complete primary school. The adjusted OR for high education in our study was 4.1, making it the highest OR for the variables included in our regression analysis. These results are in agreement with previous studies and confirm that both lower level of education and a previous unhealthy state are important negative determinants of HRQoL, ${ }^{18-20}$ and suggest that the better the previous health state, and the better the social and economic state, the higher is the chance for better recovery and hence for presumably better HRQoL. 
We would like to acknowledge several limitations that should be pointed out: the relatively high percentage of patients $(22 \%)$ who had no memories of their ICU stay compared with other studies ${ }^{21-23}$ can be explained by different sedation strategies which were not recorded on our database. Sedation could be an important confounder as those with prolonged deep sedation are bound to have less memories. In addition, those with prolonged deep sedation were probably sedated on this level because of disease severity, which on its own is related to HRQoL and survival. Retrospective assessment of HRQoL may be affected by recall bias and influenced by the critical illness, because premorbid HRQoL may be experienced as falsely high in that a present poor status may lead to overrating preadmission HRQoL..$^{19,24,25}$ Also, only one measure of HRQoL was made after ICU discharge, and it is known that HRQoL changes over time ${ }^{18,26,27}$ and therefore should be measured over time. Another important limitation is the number of non-respondents, which could have introduced selection bias; in any case, no differences were observed in the observed characteristics of the participants and non-participants. Finally, data were collected over 10 years and we do not know to what extent this might influence the results.

\section{Conclusion}

In conclusion, this study suggests that most of the ICU survivors have memories of their ICU stay 6 months after ICU discharge. Moreover, having memories of the ICU stay is significantly associated with a higher perceived HRQoL, ie, having memories of the ICU stay may be better than having no memories at all.

\section{Acknowledgments}

The authors would like to thank the ICU staff from the participating hospitals for contribution of data collection for this study.

Study coordinator: António H Carneiro (Unidade de Cuidados Intensivos Polivalente, Hospital Geral de Santo António, Porto). Study promoters: António H Carneiro (Unidade de Cuidados Intensivos Polivalente, Hospital Geral de Santo António, Porto), Eduardo Silva (Unidade de Cuidados Intensivos Polivalente, Hospital do Desterro, Lisboa), and José Artur Paiva (Unidade de Cuidados Intensivos Polivalente da Urgência, Hospital de São João, Porto). ICU participants: Augusta Amaro Serviço de Cuidados Intensivos Médicos, Hospital Pedro Hispano, Matosinhos; Ernestina Gomes, Unidade de Cuidados Intensivos Polivalente, Hospital Geral de Santo António, Porto; Ana Isabel Paixão, Unidade de Cuidados Intensivos Polivalente,
Centro Hospitalar de Vila Nova de Gaia, Vila Nova de Gaia; Francisco Esteves, Unidade de Cuidados Intensivos, Centro Hospitalar Peso da Régua Vila Real, Vila Real; Piedade Amaro, Unidade de Cuidados Intensivos, Hospital de S. Sebastião, Santa Maria da Feira; Paula Coutinho, Unidade de Cuidados Intensivos, Centro Hospitalar dos Covões, Coimbra; Eduardo Silva, Unidade de Cuidados Intensivos, Hospital do Desterro, Lisboa; Isabel Moniz, Unidade de Cuidados Intensivos, Hospital de Santa Maria, Lisboa; José Vaz, Unidade de Cuidados Intensivos, Hospital de Beja; Orquídea Ribeiro, Altamiro Costa Pereira, Serviço Biostatística e Informática Médica da Faculdade de Medicina da Universidade do Porto - Porto.

\section{Disclosure}

Armando Teixeira-Pinto was supported by NHMRC program grant 633003 to the Screening \& Test Evaluation Program (STEP). Lotti Orwelius and Cristina Lobo were supported by the grant from Fundação para a Ciência e Tecnologia (PIC/ IC/83312/2007). The authors declare that they have no other conflicts of interest in this work.

\section{References}

1. Dowdy DW, Eid MP, Sedrakyan A, et al. Quality of life in adult survivors of critical illness: a systematic review of the literature. Intensive Care Med. 2005;31(5):611-620.

2. Oeyen SG, Vandijck DM, Benoit DD, Annemans L, Decruyenaere JM. Quality of life after intensive care: a systematic review of the literature. Crit Care Med. 2010;38(12):2386-2400.

3. Antonelli M, Azoulay E, Bonten M, et al. Year in review in Intensive Care Medicine 2009: I. Pneumonia and infections, sepsis, outcome, acute renal failure and acid base, nutrition and glycaemic control. Intensive Care Med. 2010;36(2):196-209.

4. Granja C, Gomes E, Amaro A, et al. Understanding posttraumatic stress disorder-related symptoms after critical care: the early illness amnesia hypothesis. Crit Care Med. 2008;36(10):2801-2809.

5. Cardoso T, Carneiro AH, Ribeiro O, Teixeira-Pinto A, Costa-Pereira A. Reducing mortality in severe sepsis with the implementation of a core 6-hour bundle: results from the Portuguese community-acquired sepsis study (SACiUCI study). Crit Care. 2010;14(3):R83.

6. Brooks R. EuroQol: the current state of play. Health Policy. 1996;37(1): 53-72.

7. van Agt HM, Essink-Bot ML, Krabbe PF, Bonsel GJ. Test-retest reliability of health state valuations collected with the EuroQol questionnaire. Soc Sci Med. 1994;39(11):1537-1544.

8. Angus DC, Carlet J; 2002 Brussels Roundtable Participants. Surviving intensive care: a report from the 2002 Brussels Roundtable. Intensive Care Med. 2003;29(3):368-377.

9. Oster C, Willebrand M, Dyster-Aas J, Kildal M, Ekselius L. Validation of the EQ-5D questionnaire in burn injured adults. Burns. 2009;35(5): 723-732.

10. Azevedo L, Granja C, Ernestina AAG, Morujao E, Dias C, Pereira AC. Validity and reliability of EQ-5D questionnaire in critically ill patients. Crit Care Med. 2007;35:A172.

11. Jones C, Humphris G, Griffiths R. Preliminary validation of the ICUM tool: A tool for assessing memory of the intensive care experience. Clinical Intensive Care. 2000;11(5):251-255.

12. Mehlhorn J, Freytag A, Schmidt K, et al. Rehabilitation interventions for postintensive care syndrome: a systematic review. Crit Care Med. 2014;42(5):1263-1271. 
13. Rattray JE, Hull AM. Emotional outcome after intensive care: literature review. $J A d v$ Nurs. 2008;64(1):2-13.

14. Bäckman C, Orwelius L, Sjöberg F, Fredrikson M, Walther S. Long-term effect of the ICU-diary concept on quality of life after critical illness. Acta Anaesthesiol Scand. 2010;54(6):736-743.

15. Ringdal M, Plos K, Ortenwall P, Bergbom I. Memories and healthrelated quality of life after intensive care: a follow-up study. Crit Care Med. 2010;38(1):38-44.

16. Patel SB, Kress JP. Sedation and analgesia in the mechanically ventilated patient. Am J Respir Crit Care Med. 2012;185(5):486-497.

17. Girard TD, Kress JP, Fuchs BD, et al. Efficacy and safety of a paired sedation and ventilator weaning protocol for mechanically ventilated patients in intensive care (Awakening and Breathing Controlled trial): a randomised controlled trial. Lancet. 2008;371(9607):126-134.

18. Orwelius L, Nordlund A, Nordlund P, et al. Pre-existing disease: the most important factor for health related quality of life long-term after critical illness: a prospective, longitudinal, multicentre trial. Crit Care. 2010;14(2):R67.

19. Wehler M, Geise A, Hadzionerovic D, et al. Health-related quality of life of patients with multiple organ dysfunction: individual changes and comparison with normative population. Crit Care Med. 2003;31(4):1094-1101.
20. Wade DM, Howell DC, Weinman JA, et al. Investigating risk factors for psychological morbidity three months after intensive care: a prospective cohort study. Crit Care. 2012;16(5):R192.

21. Jones C, Griffiths RD, Humphris G, Skirrow PM. Memory, delusions, and the development of acute posttraumatic stress disorder-related symptoms after intensive care. Crit Care Med. 2001;29(3):573-580.

22. Ringdal M, Plos K, Bergbom I. Memories of being injured and patients' care trajectory after physical trauma. BMC Nurs. 2008;7:8.

23. Svenningsen H, Tonnesen EK, Videbech P, Frydenberg M, Christensen D, Egerod I. Intensive care delirium - effect on memories and health-related quality of life - a follow-up study. J Clin Nurs. 2014;23(5-6):634-644.

24. Dinglas VD, Gifford JM, Husain N, Colantuoni E, Needham DM. Quality of life before intensive care using EQ-5D: patient versus proxy responses. Crit Care Med. 2013;41(1):9-14.

25. Puntillo KA, Neuhaus J, Arai S, et al. Challenge of assessing symptoms in seriously ill intensive care unit patients: can proxy reporters help? Crit Care Med. 2012;40(10):2760-2767.

26. Flaatten H, Kvale R. Survival and quality of life 12 years after ICU. A comparison with the general Norwegian population. Intensive Care Med. 2001;27(6):1005-1011.

27. Ulvik A, Kvåle R, Wentzel-Larsen T, Flaatten H. Quality of life 2-7 years after major trauma. Acta Anaesthesiol Scand. 2008;52(2):195-201. 


\section{Supplementary material}

Table SI Comparison of clinical and demographic characteristics of patients who returned the questionnaires $(n=310)$ and the nonrespondents $(n=289)$ enrolled in the study by ICU memories status

\begin{tabular}{|c|c|c|c|c|c|}
\hline \multirow[b]{3}{*}{ Age (years), median (IQR) } & \multicolumn{5}{|c|}{ Eligible to participate in the study $(n=599)$} \\
\hline & \multicolumn{2}{|c|}{ Respondents ( $n=310,52 \%)$} & \multicolumn{2}{|c|}{ Non-respondents $(n=289,48 \%)$} & \multirow{2}{*}{$\begin{array}{l}\boldsymbol{P} \text {-value* } \\
0.205\end{array}$} \\
\hline & 60 & $(50-70)$ & 55 & $(39-70)$ & \\
\hline SAPS, median (IQR) & 38 & $(30-47)$ & 38 & $(28-49)$ & 0.861 \\
\hline LoS ICU, median (IQR) & 8 & $(5-13)$ & 7 & $(4-12)$ & 0.147 \\
\hline LoS hospital, median (IQR) & 21 & $(14-32)$ & 19 & $(|2-3|)$ & 0.098 \\
\hline \multicolumn{6}{|l|}{ Sex, n (\%) } \\
\hline Female & 129 & $(42)$ & 114 & (39) & 0.589 \\
\hline Male & 181 & $(58)$ & 175 & $(61)$ & \\
\hline \multicolumn{6}{|l|}{ Diagnostic category, n (\%) } \\
\hline Medical & 176 & $(57)$ & 183 & $(63)$ & 0.849 \\
\hline Trauma & 49 & (16) & 47 & (16) & \\
\hline Scheduled surgery & 34 & (II) & 26 & (9) & \\
\hline Non-scheduled surgery & 51 & $(16)$ & 33 & (II) & \\
\hline
\end{tabular}

Note: *Mann-Whitney $U$ test was used for continuous variables and chi-square test for categorical ones.

Abbreviations: ICU, intensive care unit; SAPS, Simplified Acute Physiology Score; LoS, length of stay; IQR, interquartile range.

Patient Related Outcome Measures

\section{Publish your work in this journal}

Patient Related Outcome Measures is an international, peer-reviewed, open access journal focusing on treatment outcomes specifically relevant to patients. All aspects of patient care are addressed within the journal and practitioners from all disciplines are invited to submit their work as well as healthcare researchers and patient support groups

\section{Dovepress}

The journal is included in PubMed. The manuscript management system is completely online and includes a very quick and fair peer-review system. Visit http://www.dovepress.com/testimonials.php to read real quotes from published authors.

Submit your manuscript here: http://www.dovepress.com/patient-related-outcome-measures-journal 